\title{
Evaluation of Serotonin Serum Level in Cases of Alopecia Areata and Vitiligo Fawzia Farag Mostafa ${ }^{1}$, Naglaa Ali Khalifa ${ }^{2}$, Sammar Mohammad Ibrahim*1, Ahmed Said Abdel Shafy ${ }^{1}$ \\ Departments of ${ }^{1}$ Dermatology, Venereology and Andrology, \\ ${ }^{2}$ Clinical Pathology, Zagazig University Hospital, Egypt \\ *Corresponding author: Sammar Mohammad Ibrahim, E-Mail: sammaromarmohammed@gmail.com
}

\begin{abstract}
Background: There are cutaneous illnesses that could be exacerbated or precipitated by stress, including alopecia areata, psoriasis, and even vitiligo. Psychological sequelae mainly affected by serotonin have been studied among these patients.

Objective: Assessment of blood serotonin levels in alopecia areata and vitiligo patients for psychological impacts. Patients and Methods: 15 individuals with vitiligo, 15 with alopecia areata, and 15 healthy age and sex matched controls were studied in this study. A modified version of the Social Readjustment Rating Scale (SRRS) was used to quantify the stress index, and blood serotonin levels were also measured to study the role of stress in alopecia areata and vitiligo.

Results: Patients who had alopecia areata as well as vitiligo had considerably greater serum serotonin levels than controls. In the vitiligo group, there was a strong positive connection between serum serotonin, the vitiligo area scoring index (VASI) score, and the stress index. On the other hand, no positive correlation was found between serum serotonin and both severity of alopecia tool (SALT) score and stress index in alopecia areata group. Conclusion: In both alopecia areata and vitiligo, psychological stress appears to play a significant role as a triggering factor and we should pay attention to psychiatric role to get proper treatment for such chronic diseases.

Keywords : Alopecia Areata, Serotonin, Stress, Vitiligo
\end{abstract}

\section{INTRODUCTION}

The prevalence of vitiligo, a chronic autoimmune inflammatory illness that causes skin discoloration, is between 0.5 and 1 percent all over the world. A lack of melanocytes in the epidermis causes white areas ${ }^{(\mathbf{1}, \mathbf{2})}$. Despite the fact that vitiligo does not shorten a person's life expectancy, the discoloration has a detrimental effect on their quality of life and mental health, leading to social exclusion and an increased risk of mental health problems ${ }^{(3)}$.

An auto-immune disorder called alopecia areata (AA) causes hair loss in genetically vulnerable people in reaction to unknown environmental factors (4). Alopecia areata can be triggered by stressful life situations. Even if stressful life events play only a little influence in the onset of alopecia areata, the worry and despair that accompany this long-term condition may have an impact on the course of the disease by way of stress mediators ${ }^{(5)}$.

Many diseases and pathological disorders can be aggravated or triggered by stress. Stress exacerbates illness complications, and people who are exposed to stress, such as those who work or live in high-stress environments, are more likely to suffer from a wide range of ailments ${ }^{(\boldsymbol{})}$.

Stress can contribute to cancer by lowering the body's ability to fight infection. A decrease in cytotoxic $\mathrm{T}$ lymphocyte and natural killer cell activity, as well as an increase in malignant cell proliferation, genetic instability, and tumor formation are all possible side effects of prolonged high levels of stress ${ }^{(7)}$.

Dietary tryptophan, an essential amino acid, yields serotonin (5-hydroxytryptamine), a monoamine. Central nervous system (CNS) neurotransmitter 5-HT has been implicated in a wide range of cognitive and emotional processes as well as arousal and sleep ${ }^{(8)}$.

The purpose of this study was detection of psychiatric impact among cases who have vitiligo or alopecia areata by evaluation of serum serotonin level in these patients.

\section{PATIENTS AND METHODS}

From December 2019 to July 2020, at Zagazig University Hospitals' Dermatology, Venereology, and Andrology Out-patient Clinic and Clinical Pathology Department, we conducted this study. Our trial involved 15 patients who had vitiligo, 15 patients who had alopecia areata and 15 apparently healthy age and sex matched controls.

\section{Ethical considerations:}

In order for the trial to proceed, all participants had to sign informed consent forms and submit them to Zagazig University's ethical committee (ZUIRB\#352). Ethics guidelines for human experimentation were adhered to in accordance

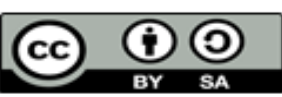

This article is an open access article distributed under the terms and conditions of the Creative Commons Attribution (CC BY-SA) license (http://creativecommons.org/licenses/by/4.0/) 
with the Helsinki Declaration of the World Medical Association.

\section{Inclusion criteria:}

Patient diagnosed clinically as vitiligo confirmed by woods light examination, patient diagnosed clinically as alopecia areata, both sexes included, age above 18 years old.

\section{Exclusion criteria:}

Patients with severe osteoporosis, an intra articular fracture involving the radiocarpal joint, active medical conditions (e.g. psychiatric disease) or malignancies, immunocompromised patients who have been diagnosed with HIV or hepatitis B or C, pregnant or lactating women, patients on antidepressant treatment, or patients on cisapride (5HT4 receptor agonist).

This is what all of the participants in this research had to go through:

1) History taking: All patients in this trial were given a specially-designed sheet to fill out:

- Personal history: Information such as their full name, date of birth, marital status, where they live, what they do for a living, and any other medically relevant information (smoking and alcohol intake).

- Present history: Full dermatologic history was obtained, including: onset, course (progressive/regressive/stationary) and duration of vitiligo or alopecia areata.

- Family history:

- Family history of alopecia areata or vitiligo.

- Family history of psychiatric disease or drug.

- Past history: Systemic diseases (e.g. autoimmune diseases like autoimmune thyroiditis), other treatments.

2) General examination: To rule out any possible systemic disease, a thorough clinical examination was necessary.

3) Examination of the skin

\section{A. Vitiligo group}

The whole body was inspected in good day light for: Number of vitiligo patches that have been discovered, the vitiligo's anatomical distribution, vitiligo types and VASI scoring (Fig. 1).

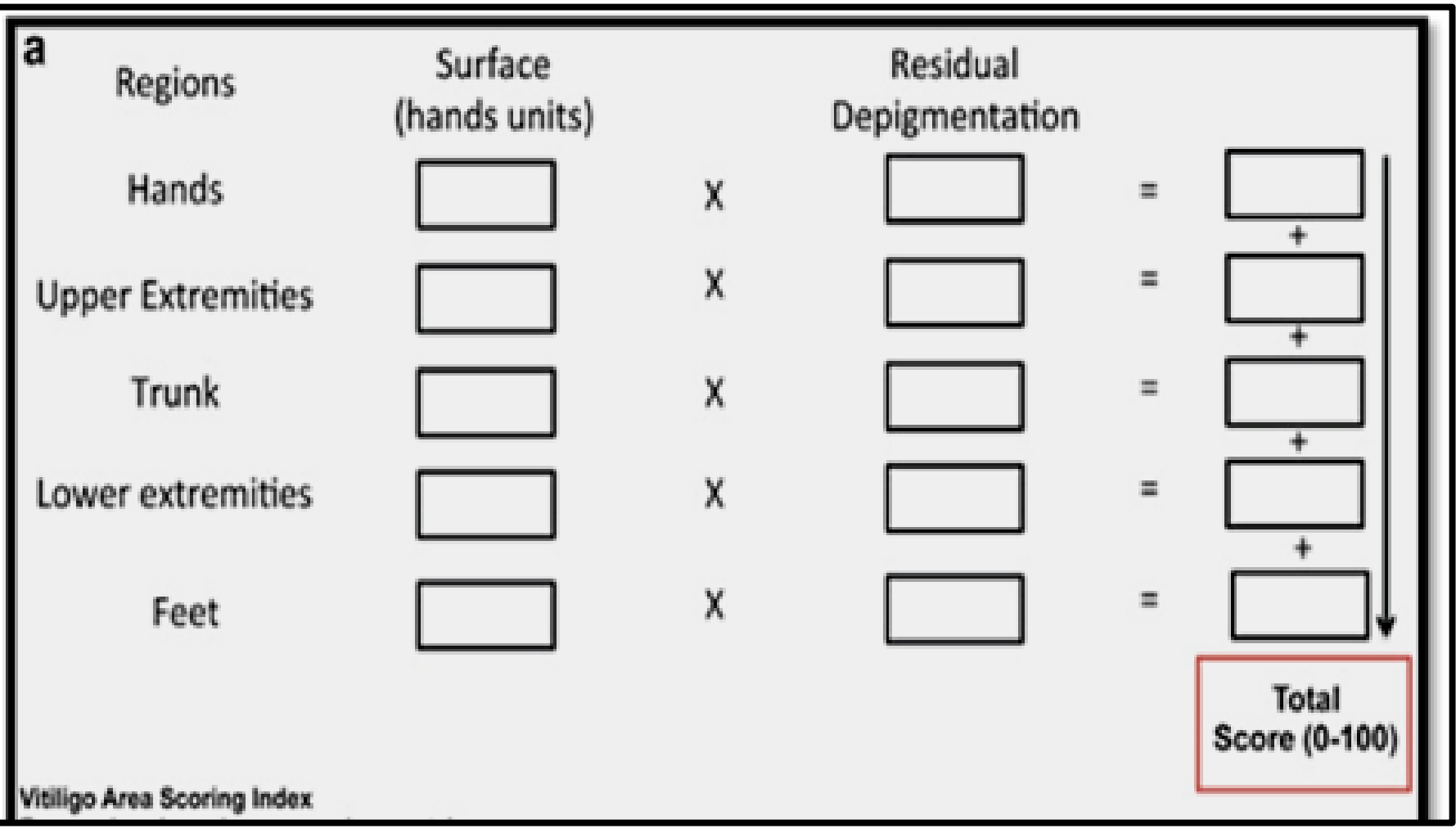

Fig. (1): VASI score of vitiligo (9). 
The degree of hair loss on the scalp was assessed:

The Severity of Alopecia Tool score was developed by the working committee of the National Alopecia Areata Foundation (SALT score). A person's scalp was separated into four sections based on their facial features: Vertex $40 \%$ of the scalp surface area (0.4) and the right profile of scalp $0.18 \%$ of the scalp surface area, left side of the scalp profile $18 \%(0.18)$ of scalp surface area, 24\% (0.24) of scalp surface area on the backside. When calculating a person's hair loss rate, they multiply the percentage of hair loss they've lost by their scalp surface area. Total hair loss in all of the above-mentioned regions is used to calculate a person's SALT score ${ }^{(\mathbf{1 0 )} \text {. }}$

Evaluation of stress index: The Social Readjustment Rating Scale was updated to ask questions about stress before the beginning or progression of alopecia areata and vitiligo. For both the patients and the controls, we adapted questions from Holmes and Rahe's Social Readjustment Rating Scale.

Determination of serum serotonin level: Measurement of serum serotonin by ELISA kit provided by Sunred/China.

\section{Statistical analysis}

In order to analyze the data acquired, they were loaded into a computer and run via the Statistical Package of the Social Services (SPSS), version 25. Tables and graphs were used to present the findings. The Shapiro-Wilk test was used to check normal distribution of quantitative data. Quantitative data were presented as means \pm standard deviation (SD), median, and range and were compared by KruskalWallis (KW) test as they were not-normally distributed, and if the difference was significant, then LSD test was used as a post-hoc test for multiple comparison. Qualitative data were presented as frequency and percentage and were compared by Pearson chi-square test $\left(\chi^{2}\right)$. P value equals or less than 0.05 was considered significant.

\section{RESULTS}

When it came to the age and gender distribution, there were no statistically significant differences among any of the groups (Table 1).

\section{Table (1): Demographic data}

\begin{tabular}{|c|c|c|c|c|c|c|c|c|c|}
\hline \multicolumn{2}{|c|}{ Variable } & \multicolumn{2}{|c|}{$\begin{array}{c}\text { Group I (Vitiligo) } \\
(n=15)\end{array}$} & \multicolumn{2}{|c|}{$\begin{array}{c}\text { Group II (Alopecia A.) } \\
(n=15)\end{array}$} & \multicolumn{2}{|c|}{$\begin{array}{c}\text { Group III (Control) } \\
(n=15)\end{array}$} & KW & $\mathbf{P}$ \\
\hline $\begin{array}{l}\text { Age: } \\
\text { (years) }\end{array}$ & $\begin{array}{c}\text { Mean } \pm \text { SD } \\
\text { Median } \\
\text { Range }\end{array}$ & $\begin{array}{r}30.53 \\
2 \\
18\end{array}$ & & & & & & 2.11 & 0.35 \\
\hline \multicolumn{2}{|c|}{ Variable } & No & $\%$ & No & $\%$ & No & $\%$ & $\chi^{2}$ & $\mathbf{P}$ \\
\hline Sex: & $\begin{array}{c}\text { Female } \\
\text { Male }\end{array}$ & $\begin{array}{c}12 \\
3\end{array}$ & $\begin{array}{l}80 \\
20\end{array}$ & $\begin{array}{l}7 \\
8\end{array}$ & $\begin{array}{l}46.7 \\
53.3\end{array}$ & $\begin{array}{c}11 \\
4\end{array}$ & $\begin{array}{l}73.3 \\
26.7\end{array}$ & 4.20 & 0.12 \\
\hline
\end{tabular}

The clinical data of the studied patients are shown in table 2. Most vitiligo patients had active progressive course and the most common sites were upper and lower limbs followed by trunk. In alopecia areata group most of the patients had active progressive course and the common sites were vertex and beard.

Table (2): Clinical data of the two studied groups of cases

\begin{tabular}{|c|c|c|c|c|c|}
\hline \multicolumn{2}{|c|}{ Variable } & \multirow{2}{*}{\multicolumn{2}{|c|}{$\begin{array}{c}\text { Group I (vitiligo) }(\boldsymbol{n}=\mathbf{1 5}) \\
6.27 \pm 6.31 \\
4\end{array}$}} & \multirow{2}{*}{\multicolumn{2}{|c|}{$\begin{array}{c}\text { Group II (alopecia) }(\boldsymbol{n}=\mathbf{1 5}) \\
0.75 \pm 0.94 \\
0.5\end{array}$}} \\
\hline \begin{tabular}{|l|}
$\begin{array}{l}\text { Duration: } \\
\text { (years) }\end{array}$ \\
\end{tabular} & $\begin{array}{l}\text { Mean } \pm \text { SD } \\
\text { Median }\end{array}$ & & & & \\
\hline \begin{tabular}{|l|} 
Severity \\
score:
\end{tabular} & Mean \pm SD & \multicolumn{2}{|c|}{$\begin{array}{c}\text { (VASI) } \\
6.02 \pm 11.18\end{array}$} & \multicolumn{2}{|c|}{$\begin{array}{c}\text { (SALT) } \\
10.78 \pm 8.63 \\
\end{array}$} \\
\hline Variable & & No & $\%$ & No & $\%$ \\
\hline $\begin{array}{l}\text { Family } \\
\text { history: }\end{array}$ & $\begin{array}{l}\text {-ve } \\
+\mathrm{ve}\end{array}$ & $\begin{array}{c}10 \\
5\end{array}$ & $\begin{array}{l}66.7 \\
33.3\end{array}$ & $\begin{array}{c}11 \\
4\end{array}$ & $\begin{array}{l}73.3 \\
26.7\end{array}$ \\
\hline Activity: & $\begin{array}{l}\text { Active progressive course } \\
\text { Stable }\end{array}$ & $\begin{array}{c}14 \\
1\end{array}$ & $\begin{array}{c}93.3 \\
6.7\end{array}$ & $\begin{array}{c}13 \\
2 \\
\end{array}$ & $\begin{array}{l}86.7 \\
13.3 \\
\end{array}$ \\
\hline Site: & $\begin{array}{l}\text { Face } \\
\text { Neck } \\
\text { Upper limb } \\
\text { Lower limb } \\
\text { Trunk } \\
\text { Back } \\
\text { Buttock }\end{array}$ & $\begin{array}{c}2 \\
3 \\
14 \\
14 \\
8 \\
1 \\
1\end{array}$ & $\begin{array}{c}13.3 \\
20 \\
93.3 \\
93.3 \\
53.3 \\
6.7 \\
6.7\end{array}$ & --- & --- \\
\hline Site: & $\begin{array}{l}\text { Beard } \\
\text { Vertex } \\
\text { Back of scalp } \\
\text { Top } \\
\text { Sides of scalp } \\
\end{array}$ & -- & --- & $\begin{array}{l}6 \\
7 \\
5 \\
1 \\
3 \\
\end{array}$ & $\begin{array}{c}40 \\
46.7 \\
33.3 \\
6.7 \\
20 \\
\end{array}$ \\
\hline
\end{tabular}


Concerning stress index in groups I and II, it was highly significantly increased compared to group III (Table 3).

Table (3): Stress index among the studied groups

\begin{tabular}{|c|c|c|c|c|c|c|c|}
\hline \multicolumn{2}{|c|}{ Variable } & $\begin{array}{c}\text { Group I } \\
(\text { Vitiligo) } \\
(\text { n=15) }\end{array}$ & $\begin{array}{c}\text { Group II } \\
(\text { Alopecia A.) } \\
(\text { n=15) }\end{array}$ & $\begin{array}{c}\text { Group III } \\
(\text { Control) } \\
(\mathbf{n = 1 5})\end{array}$ & KW & P & LSD \\
\hline $\begin{array}{l}\text { Stress } \\
\text { index: }\end{array}$ & $\begin{array}{c}\text { Mean } \pm \text { SD } \\
\text { Median }\end{array}$ & $\begin{array}{c}428.47 \pm 54.79 \\
420\end{array}$ & $\begin{array}{c}396.6 \pm 73.49 \\
400\end{array}$ & $\begin{array}{c}146.33 \pm 54.72 \\
130\end{array}$ & 30.71 & $\begin{array}{c}<0.001 \\
* *\end{array}$ & $\begin{array}{c}<0.001^{* *} \\
<0.001^{* *}\end{array}$ \\
\hline
\end{tabular}

$* *$ : Highly significant

When it came to serum serotonin levels, it was found that group I and II were statistically increased from group III (Table 4).

Table (4): Serum serotonin level among the studied groups

\begin{tabular}{||l|c|c|c|c|c|c|c||}
\hline \multicolumn{2}{|c|}{ Variable } & $\begin{array}{c}\text { Group I } \\
(\text { Vitiligo) } \\
(\mathbf{n = 1 5})\end{array}$ & $\begin{array}{c}\text { Group II } \\
(\text { Alopecia } \\
\text { A.) } \\
(\mathbf{n = 1 5})\end{array}$ & $\begin{array}{c}\text { Group III } \\
(\text { Control) } \\
(\mathbf{n = 1 5})\end{array}$ & KW & P & LSD \\
\hline $\begin{array}{l}\text { Serotonin: } \\
\text { ng/ml }\end{array}$ & $\begin{array}{c}\text { Mean } \pm \\
\text { SD } \\
\text { Median }\end{array}$ & $\begin{array}{c}34.53 \pm \\
18.58\end{array}$ & $\begin{array}{c}31.64 \pm 12.66 \\
33.52\end{array}$ & $\begin{array}{c}7.42 \pm 1.49 \\
7.4\end{array}$ & 29.36 & $\begin{array}{c}<0.001 \\
* *\end{array}$ & $\begin{array}{c}0.93 \mathrm{NS} \\
<0.001 * * \\
<0.001 * *\end{array}$ \\
\hline
\end{tabular}

**: Highly significant

There was statistical significance positive correlation between serum serotonin levels, VASI score and stress index in group I only (Table 5).

Table (5): Correlation between serotonin, age, duration, severity and stress index among the studied groups

\begin{tabular}{|c|c|c|c|c|c|c|}
\hline \multirow{3}{*}{ Variable } & \multicolumn{6}{|c|}{ Serotonin (ng/ml) } \\
\hline & \multicolumn{2}{|c|}{$\begin{array}{c}\text { Group I } \\
(n=15)\end{array}$} & \multicolumn{2}{|c|}{$\begin{array}{c}\text { Group II } \\
(n=15)\end{array}$} & \multicolumn{2}{|c|}{$\begin{array}{c}\text { Group III } \\
(n=15)\end{array}$} \\
\hline & $\mathbf{r}$ & $\mathbf{P}$ & $\mathbf{r}$ & $\mathbf{P}$ & $\mathbf{R}$ & $\mathbf{P}$ \\
\hline Age (years) & 0.40 & 0.14 & 0.09 & 0.76 & 0.04 & 0.89 \\
\hline Disease duration (years) & 0.48 & 0.07 & 0.47 & 0.08 & ---- & ---- \\
\hline $\begin{array}{l}\text { Vitiligo area scoring index } \\
\text { (VASI) }\end{array}$ & 0.79 & $<0.001 * *$ & ---- & ----- & ---- & ---- \\
\hline Severity of alopecia tool (SALT) & $\begin{array}{ll}--- \\
\end{array}$ & $\begin{array}{ll}---- \\
-\cdots\end{array}$ & 0.15 & 0.60 & $\begin{array}{ll}--- \\
-\end{array}$ & $\begin{array}{c}--- \\
--\end{array}$ \\
\hline Stress index & 0.52 & $0.04 *$ & 0.09 & 0.76 & 0.34 & 0.21 \\
\hline
\end{tabular}

*: Significant, **: Highly significant

There was statistical significant positive correlation between stress index and VASI score in group I (Table 6, Figure 2).

Table (6): Correlation between severity and stress index among the studied groups of cases

\begin{tabular}{|l|c|c|c|c|}
\hline \multirow{2}{*}{ Variable } & \multicolumn{2}{c|}{$\begin{array}{c}\text { Group I }(\boldsymbol{n}=\mathbf{1 5}) \\
\text { VASI }\end{array}$} & \multicolumn{2}{c|}{ Group II $(\boldsymbol{n}=15)$} \\
SALT
\end{tabular}

*: Significant 


\section{Group I}

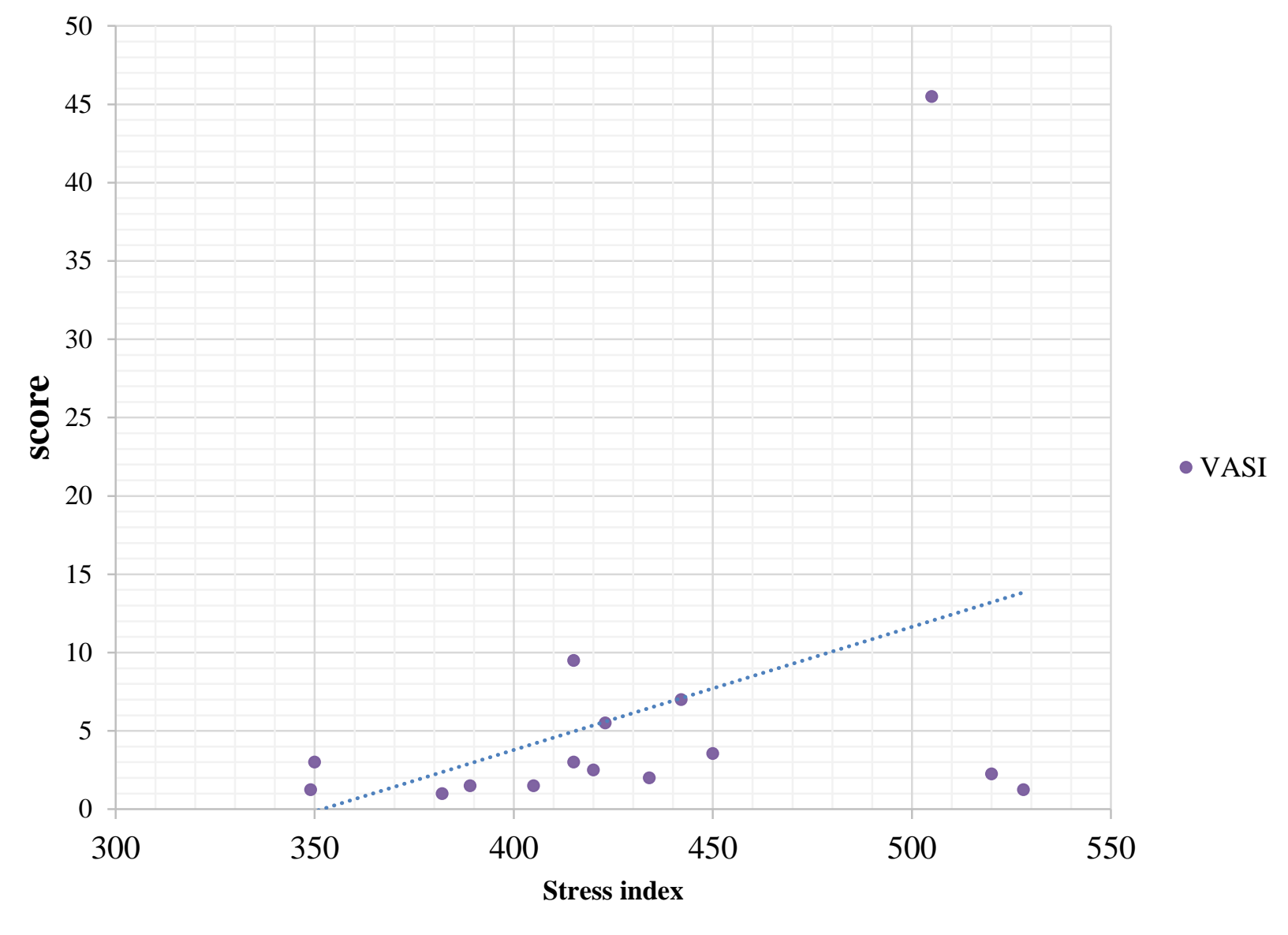

Figure (2): Correlation between stress index and VASI scores in Group I.

\section{DISCUSSION}

Due to the psychological discomfort caused by the associated symptoms and stigma connected with a highly visible skin illness like vitiligo, the quality of life of the patient is significantly impaired ${ }^{(11,12)}$.

In the human body, stress has long been linked to a decrease in the body's ability to fight infection. The proinflammatory cytokine cascade can be amplified by prolonged stress, which suppresses the adaptive immune system as well as the innate immune system (natural killer cell activity) ${ }^{(\mathbf{1 3})}$.

In the human body, stress and immunity are intimately linked, according to González-Parra and Daudén ${ }^{(14)}$. The adaptive immune system and the innate immune system (natural killer cell activity) are both affected by prolonged stress, which can lead to an increase in the proinflammatory cytokine cascade. Autonomic nervous system stimulation of hypothalamus-pituitary adrenal axis is the mechanism behind this.

In both of vitiligo and alopecia areata groups, there were no statistically significant differences in the distribution of sexes or age. Our result was matched with Manolache and Benea ${ }^{\left({ }^{15}\right)}$ who found there was no statistically significant difference regarding sex and age.

Concerning the duration among vitiligo cases, it was 6.27 years. VASI score in vitiligo cases ranged from one to 45.5 with mean 6.02. Positive family history was found in $33.3 \%$ of vitiligo cases. Vitiligo patients showed an active progressive course (93.3\%). Most common site of vitiligo were upper and lower limbs followed by trunk. The duration among alopecia areata group was 9 months. SALT score in alopecia areata cases ranged from 0.75 to 29.7 with mean 10.78. Positive family history in alopecia areata cases was $26.7 \%$. Alopecia areata cases had an active progressive course $(86.7 \%)$. In alopecia most common sites were vertex and beard.

In our study alopecia areata group female represented $(53.3 \%)$ while male represented $(46.7 \%)$ and the median age was $(32.73 \pm 7.86)$. In vitiligo group there was female predominance $(80 \%)$ while male represented $(20 \%)$ and the median age was $(30.53 \pm 14.53)$. There was no statistically significant differences between the studied groups in age or sex. This was matched with Manolache and Benea ${ }^{(15)}$ in which alopecia areata adult group female ratio was $(60 \%)$ and male ratio was (40\%) and the median age 
was $(30.6 \pm 11.96)$. In the vitiligo group, women outnumbered men 68.75 percent to $31.25 \%$, with a mean age of 33.87 years old and a standard deviation of 17.78 years. The median age of men and women in the alopecia areata and vitiligo groups was not statistically different.

In our study there was a high statistically significant result concerning stress index in alopecia areata group. Regarding stress index in vitiligo group, there was a high statistically significant result. In both alopecia and vitiligo, stress appears to play a significant role, hence we consider stress a precipitating factor in both groups investigated. Manolache (16) was in agreement with our study. Stressful occurrences were shown to be significantly different between alopecia areata sufferers and control subjects. Stressful events have been linked to more than half of all cases of alopecia areata in adults, according to a new study. In Khoshdel et al. ${ }^{(17)}$ study, to assess the occurrence of stressful events, they used the Holmes and Rahe's Social Readjustment Rating Scale, they found that 73.9 percent of alopecia areata patients had encountered stressful events before to the development of alopecia but also with the recurrence of the condition in the last six months. While Tan $\boldsymbol{e t}$ al. ${ }^{(18)}$ reported that only $9.8 \%$ of patients with alopecia areata experienced stress before losing their hair, van der Steen et al. ${ }^{(19)}$ discovered that only $6.7 \%$ of patients who had severe alopecia areata had stress before losing their hair.

There were more stressful situations experienced by patients with vitiligo than by control subjects, according to our research (mean \pm SD $=428.47 \pm 54.79$ ). There was a highly statistically significant result concerning stress index in vitiligo group. Manolache and Benea ${ }^{(\mathbf{1 5})}$ found that $(65.62 \%)$ of vitiligo patient between seven patients in the control group and those with vitiligo, there was a significant difference in the mean number of stressful episodes.

According to a study by Firooz and colleagues (20), $62.5 \%$ of patients believed that stress was a factor in the start of vitiligo. A high number of stressful events occurred in the year prior to vitiligo's beginning in patients, although this was not the case in controls. As previously stated, Agarwal (21) found that half of vitiligo patients had experienced stressful situations before to the disease's emergence. In contrast, no differences were detected between vitiligo patients and controls in the overall number of stressful episodes by Picardi et al. ${ }^{\text {(22) }}$.

In the present study, highly statistical significant increase in stressful events as a precipitating factor was observed among vitiligo patients and in alopecia areata patients compared to control. This was in agreement with multiple studies as according to Manolache and Benea ${ }^{(15)}$, more than 65 percent of alopecia areata and vitiligo patients identified stress as a precipitating or exacerbating factor.
In the present study, a statistically significant increase in serotonin serum level was observed among alopecia areata patients compared to control. This was in agreement with Huang et al. ${ }^{(23)}$ who reported higher levels of serum serotonin in the alopecia areata patients than in the control.

There was a statistically significant increase in serum levels of serotonin in the vitiligo patients in comparison to controls, the same result was also demonstrated by other studies as Kotb El-Sayed $\boldsymbol{e t}$ al. (24) study who reported that serotonin serum levels were significantly higher in vitiligo patients compared with controls

Serum serotonin levels correlated positively with VASI scores and the stress index in group I of our investigation. The SALT score and stress index did not correlate with serum serotonin in group II, on the other hand. Serotonin levels were not associated with sex, family history, or illness activity in Group II participants.

Finally both stress index and serotonin had a role in the onset of both alopecia areata and vitiligo as a precipitating factor. In the vitiligo group stress index and serum serotonin levels were matched with the clinical extension of the disease but they were not matched with the clinical extension in alopecia areata group.

\section{CONCLUSION:}

In both alopecia areata and vitiligo, psychological stress appears to play a significant role as a triggering factor and we should pay attention to psychiatric role to get proper treatment for such chronic diseases.

\section{Financial support and sponsorship: Nil. Conflict of interest: Nil.}

\section{REFERENCES}

1. Elbuluk N, Ezzedine K (2017): Quality of life, burden of disease, co-morbidities, and systemic effects in vitiligo patients. Dermatol Clin., 35(2):117-128.

2. Boniface K, Seneschal J, Picardo M et al. (2018): Vitiligo: Focus on clinical aspects, immunopathogenesis, and therapy. Clin Rev Allergy Immunol., 54(1):52-67.

3. Hamidizadeh $\mathrm{N}$, Ranjbar S, Ghanizadeh A et al. (2020): Evaluating prevalence of depression, anxiety and hopelessness in patients with vitiligo on an Iranian population. Health Qual Life Outcomes, 18(1):20-24.

4. Meah N, Wall D, York K et al. (2020): The alopecia areata consensus of experts (ACE) study: Results of an international expert opinion on treatments for alopecia areata. J Am Acad Dermatol., 83(1):123-130.

5. Matzer F, Egger J, Kopera D (2011): Psychosocial stress and coping in alopecia areata: a questionnaire survey and qualitative study among 45 patients. Acta Derm Venereol., 91(3):318-27.

6. Yaribeygi H, Panahi Y, Sahraei H et al. (2017): The impact of stress on body function: A review. Excli J., 16:1057-1072. 
7. Reiche E, Nunes S, Morimoto H (2004): Stress, depression, the immune system, and cancer. Lancet Oncol., 5(10):617-25.

8. Spohn S, Mawe G (2017): Non-conventional features of peripheral serotonin signaling - the gut and beyond. Nat Rev Gastroenterol Hepatol., 14(7):412-420.

9. Hamzavi I, Jain H, McLean D et al. (2004): Parametric modeling of narrowband UV-B phototherapy for vitiligo using a novel quantitative tool: the Vitiligo Area Scoring Index. Arch Dermatol., 140(6):677-683.

10. Olsen E, Hordinsky M, Price $V$ et al. (2004): Alopecia areata investigational assessment guidelinesPart II. National Alopecia Areata Foundation. J Am Acad Dermatol., 51: 440-7.

11. Hedayat $K$, Karbakhsh $M$, Ghiasi $M$ et al. (2016): Quality of life in patients with vitiligo: a crosssectional study based on Vitiligo Quality of Life index (VitiQoL). Health Qual Life Outcomes, 14:86-91.

12. Rencz F, Gula'csi L, Pe'ntek M et al. (2016): Alopecia areata and health-related quality of life: a systematic review and meta-analysis. Br J Dermatol., 175(3):561-71.

13. Wardhana $M$, Windari $M$, Puspasari $N$ et al. (2019): Role of serotonin and dopamine in psoriasis: A case-control study. Open Access Maced J Med Sci., 7(7):1138-1142.

14. González-Parra $S$, Daudén E (2019): Psoriasis and depression: The role of inflammation. Actas Dermosifiliogr., 110(1):12-19.

15. Manolache $\mathbf{L}$, Benea $\mathbf{V}$ (2007): Stress in patients with alopecia areata and vitiligo. J Eur Acad Dermatol Venereol., 21(7):921-8.

16. Manolache $L$ (2012): Psychosocial Aspects in Alopecia Areata: Studies on Stress Involvement in
Adults and Children. Nova Science Publishers, Inc; PP. 23-43.

https://www.researchgate.net/publication/291343057

_Psychosocial_aspects_in_alopecia_areata_Studies_i n_stress_involvement_in_adults_and_children

17. Khoshdel A, Shekari A, Paydary K et al. (2016): Alopecia areata: The role of stressful events and an estimate of lifetime risk in first-degree relatives, J Arch Mil Med., 4(1): 363-69.

18. Tan E, Tay Y, Goh C et al. (2002): The pattern and profile of alopecia areata in Singapore-a study of 219 Asians. Int J Dermatol., 41(11):748-53.

19. van der Steen $P$, Boezeman J, Duller P et al. (1992): Can alopecia areata be triggered by emotional stress? An uncontrolled evaluation of 178 patients with extensive hair loss. Acta Derm Venereol., 72(4):279. 80.

20. Firooz A, Bouzari N, Fallah N et al. (2004): What patients with vitiligo believe about their condition. Int J Dermatol., 43(11):811-4.

21. Agarwal G (1998): Vitiligo an under-estimated problem. Fam Pract., 15: 19-23.

22. Picardi A, Pasquini P, Cattaruzza M et al. (2003): Stressful life events, social support, attachment security and alexithymia in vitiligo. A case-control study. Psychother Psychosom., 72(3):150-8.

23. Huang J, Gong Q, Li G et al. (2004): Serotonin in alopecia areata: an enzyme immunoassay study. Int $\mathbf{J}$ Dermatol., 43(1):78-80.

24. Kotb El-Sayed M, Abd El-Ghany A, Mohamed R (2018): Neural and endocrinal pathobiochemistry of vitiligo: Comparative study for a hypothesized mechanism. Front Endocrinol (Lausanne), 9: 197-202. 